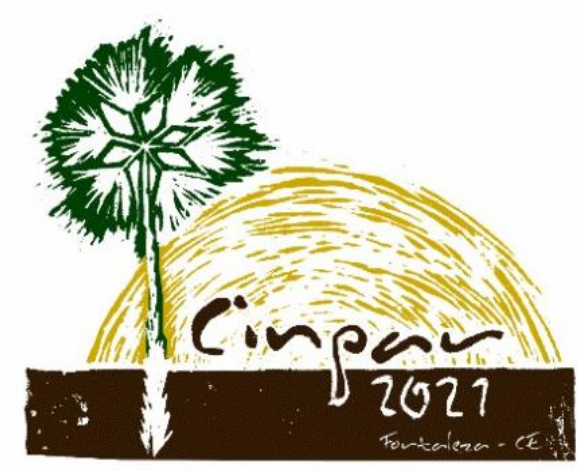

XVII Congresso Internacional sobre Patologia e

Reabilitação das Construções

XVII Congreso Internacional sobre Patología y Rehabilitación de las Construcciones

XVII International Conference on Pathology and Constructions Rehabilitation

FORTALEZA (Brasil), 3 a 5 de junho de 2021

https://doi.org/10.4322/CINPAR.2021.096

\title{
Contribuição à análise de pastas de cal hidráulica e cal hidratada para reparos em revestimentos de fachadas de edificações históricas
}

\section{Contribution to the analysis of hydraulic lime and hydrated lime pastes to repairs in facades coatings from historical buildings}

\author{
Jéssica Deise BERSCH ${ }^{1}$, Emili CAPPELARI ${ }^{2}$, Caroline GIORDANI ${ }^{3}$, Fernanda Lamego GUERRA ${ }^{4}$, Rafaela Falcão \\ SOCOLOSKI ${ }^{5}$, Angela Borges MASUERO ${ }^{6}$

\footnotetext{
${ }^{1}$ Universidade Federal do Rio Grande do Sul, Porto Alegre, Brasil, jessicadbersch@gmail.com

2 Universidade Federal do Rio Grande do Sul, Porto Alegre, Brasil, emili_cappelari@hotmail.com

${ }^{3}$ Universidade Federal do Rio Grande do Sul, Porto Alegre, Brasil, giordani.carol@gmail.com

${ }^{4}$ Universidade Federal do Rio Grande do Sul, Porto Alegre, Brasil, f.lamegoguerra@gmail.com

${ }^{6}$ Universidade Federal do Rio Grande do Sul, Porto Alegre, Brasil, angela.masuero@ufrgs.br
} \\ ${ }^{5}$ Universidade Federal do Rio Grande do Sul, Porto Alegre, Brasil, rafaela_socoloski@hotmail.com
}

Resumo: O objetivo deste trabalho é contribuir para a determinação dos ligantes de argamassa para reparo de revestimentos em fachadas de prédios históricos. Para isso, pastas com as seguintes proporções de cal hidráulica e hidratada, respectivamente, foram confeccionadas: $100 \%$ e $0 \%$; $90 \%$ e $10 \%$; $70 \%$ e $30 \%$; $50 \%$ e $50 \%$. Ensaios de resistência à compressão foram realizados aos 28 e aos 56 dias; para os 56 dias, 5 amostras de cada proporção foram curadas somente em câmara climatizada e outras 5 foram expostas em uma câmara de carbonatação com $5 \%$ de $\mathrm{CO}_{2}$ por 20 dias. As condições de carbonatação das amostras foram observadas com fenolftaleína. Ainda, ensaios de absorção de água por capilaridade foram realizados aos 91 dias. Quanto às amostras não expostas na câmara de carbonatação, aos 28 dias, observou-se a menor resistência à compressão para as pastas com $50 \%$ de cada tipo de cal em relação às demais, que não apresentaram diferença estatisticamente significativa entre si. Aos 56 dias, as resistências aumentaram conforme o teor de cal hidráulica. Também aos 56 dias, a exposição das amostras na câmara de carbonatação gerou aumento de, pelo menos, 4 vezes na resistência; ainda, entre as amostras com 70\%, 90\% e 100\% de cal hidráulica, não houve diferença estatisticamente significativa. Verificou-se com fenolftaleína que apenas as amostras expostas na câmara de carbonatação estavam totalmente carbonatadas. Para a absorção de água, aos 5 minutos de ensaio, maiores teores de cal hidráulica conduziram a menores valores de absorção.

Palavras-chave: Pastas. Cal hidráulica. Cal hidratada. Edificações históricas. Revestimentos de argamassa.

\begin{abstract}
The aim of this work is to contribute to the determination of mortar binders to repair coatings of historical buildings facades. To this end, pastes with the following proportions of hydraulic and hydrated lime, respectively, were blended: $100 \%$ and $0 \% ; 90 \%$ and $10 \% ; 70 \%$ and $30 \% ; 50 \%$ and $50 \%$. Compression strength tests were executed at 28 and at 56 days; at 56 days, 5 samples of each proportion were cured only at a climatized chamber and another 5 were also exposed to a carbonation chamber with $5 \% \mathrm{CO}_{2}$ for 20 days. The carbonation conditions of the samples were observed with phenolphthalein. Besides, water absorption by capillarity tests were performed at 91 days. Regarding the samples which were not exposed to the carbonation chamber, at 28 days, the lowest compression strength was observed for the pastes with $50 \%$ of each type of lime in relation to the others, however, the other samples did not present a statistically significant difference between them. At 56 days, the strength values increased according to the hydraulic lime content. Also, at 56 days, the exposition of samples to the carbonation chamber resulted in an increase
\end{abstract}


of at least 4 times on the strength; and there is no significant difference between the samples with $70 \%, 90 \%$, and $100 \%$ of hydraulic lime. It was verified with phenolphthalein that only the samples exposed in the carbonation chamber were fully carbonated. For water absorption by capillarity, at 5 minutes of testing, higher proportions of hydraulic lime led to lower absorption values.

Keywords: Pastes. Hydraulic lime. Hydrated lime. Historical buildings. Mortar coatings.

\section{Introdução}

As fachadas das edificações, componentes do seu invólucro externo, são essenciais para a concepção arquitetônica e a valorização do entorno, e, além disso, também são protagonistas no mecanismo de trocas entre o interior e o exterior das edificações (FLORES-COLEN et al., 2009), protegendo-as dos agentes atmosféricos (BAUER et al., 2020). Considerando-se as edificações históricas como patrimônio arquitetônico das sociedades, suas fachadas adquirem importância fundamental para a comunidade de que fazem parte.

A necessidade de conservação e preservação do patrimônio edificado para as futuras gerações contribui na justificativa pelo estudo de revestimentos de argamassa com base em cal, devido a sua importância na preservação de alvenarias antigas (BARBERO-BARRERA et al., 2014). Argamassas de cal com diferentes tipos de agregados foram utilizadas em acabamentos exteriores e interiores de edificações durante milênios e até meados do século XX (VEIGA et al., 2004a). Diversos estudos experimentais corroboram essa afirmação, entre eles o de Guerra et al. (2020), que identificou a composição com base em cal do revestimento de argamassa da edificação histórica Casa Frasca, construída no início do século XX e localizada na cidade de Porto Alegre, estado do Rio Grande do Sul, Brasil, e o de Bersch et al. (2020), referente às edificações históricas Château e Observatório Astronômico, contemporâneas à Casa Frasca e também localizadas em Porto Alegre.

O conhecimento dos materiais e das técnicas tradicionais envolvidos na confecção de argamassas de cal é, para Barbero-Barrera et al. (2014), um dos pontos-chave para sua manutenção e conservação, considerando o reparo de revestimentos existentes e a definição de novos traços. Araújo et al. (2020) explicam que conhecer os parâmetros físicos, mecânicos e de durabilidade de materiais antigos é imprescindível para se compreender o desempenho global de prédios históricos e planejar ações de manutenção e reabilitação.

Quanto aos tipos de cal, a cal hidratada é composta por hidróxidos de cálcio, podendo conter também hidróxidos de magnésio e óxidos livres, e seu endurecimento é resultante da carbonatação dos hidróxidos (CINCOTTO et al., 2007). O termo cal aérea, segundo Zhang et al. (2018), normalmente faz referência também à cal hidratada. Já a cal hidráulica compreende compostos hidráulicos e cal hidratada, sendo resultado da calcinação de calcário argiloso e posterior hidratação por meio da adição da quantidade de água necessária para reação com a cal virgem, sendo mantidos o silicato e o aluminato anidros; cales misturadas a pozolanas ou escórias de alto-forno também podem ser consideradas hidráulicas (CINCOTTO et al., 2007).

Dentre os estudos com este material, pode-se citar o de Garijo et al. (2020), que avaliou o efeito da idade nas propriedades mecânicas de argamassas com cal hidráulica ou aérea, e o de Zhang et al. (2018), que comparou propriedades físicas, mecânicas, microestrutura e outros, para argamassas de cal hidráulica natural, cal aérea com cimento e cal aérea com escória. Já Rani et al. (2021) avaliaram a porosidade de argamassas históricas de cal e identificaram a necessidade de combinar diferentes métodos de análise para possibilitar que as argamassas de reparo apresentem porosidade similar à original. Magalhães e Veiga (2005), por sua vez, produziram argamassas de cal aérea em pó e cal hidráulica e avaliaram seu comportamento mecânico e frente à água, comparando-o, inclusive, ao de uma argamassa de cal aérea hidratada em pó. Alvarez et al. (2005) recomendam que, na confecção de argamassas com cal hidratada, seja adicionado um composto com atividade pozolânica, ou, como alternativa, que se adicione a cal hidráulica em proporções adequadas.

Há, portanto, um interesse de longo prazo e ainda atual a respeito do comportamento dos materiais e das técnicas envolvidas com os revestimentos de cal. Nesse contexto, este trabalho objetiva contribuir para o conhecimento a respeito de argamassas de cal para serem utilizadas como reparo em fachadas de edificações 
históricas, por meio do estudo e análise de pastas. Segundo Arandigoyen et al. (2005), o conhecimento das pastas permite compreender o comportamento da fração ligante da argamassa.

Foram realizadas misturas dos aglomerantes cal hidráulica e cal hidratada em diferentes proporções, para compreender o seu desempenho quanto à resistência mecânica e à absorção de água por capilaridade. Ressalta-se que, apesar de este estudo comparar propriedades de diferentes ligantes comumente utilizados em restauro, o parâmetro a ser adotado em uma argamassa para intervenção deve ser sempre relacionado à caracterização física, química e mecânica do material original de cada prédio em estudo.

\section{Materiais e métodos}

Nesta seção são descritos os materiais utilizados e os métodos empregados para mistura e cura, bem como para avaliação das pastas de cal quanto à resistência à compressão e à absorção de água por capilaridade. Um fluxograma de compilação das etapas do presente trabalho está apresentado na Figura 1.

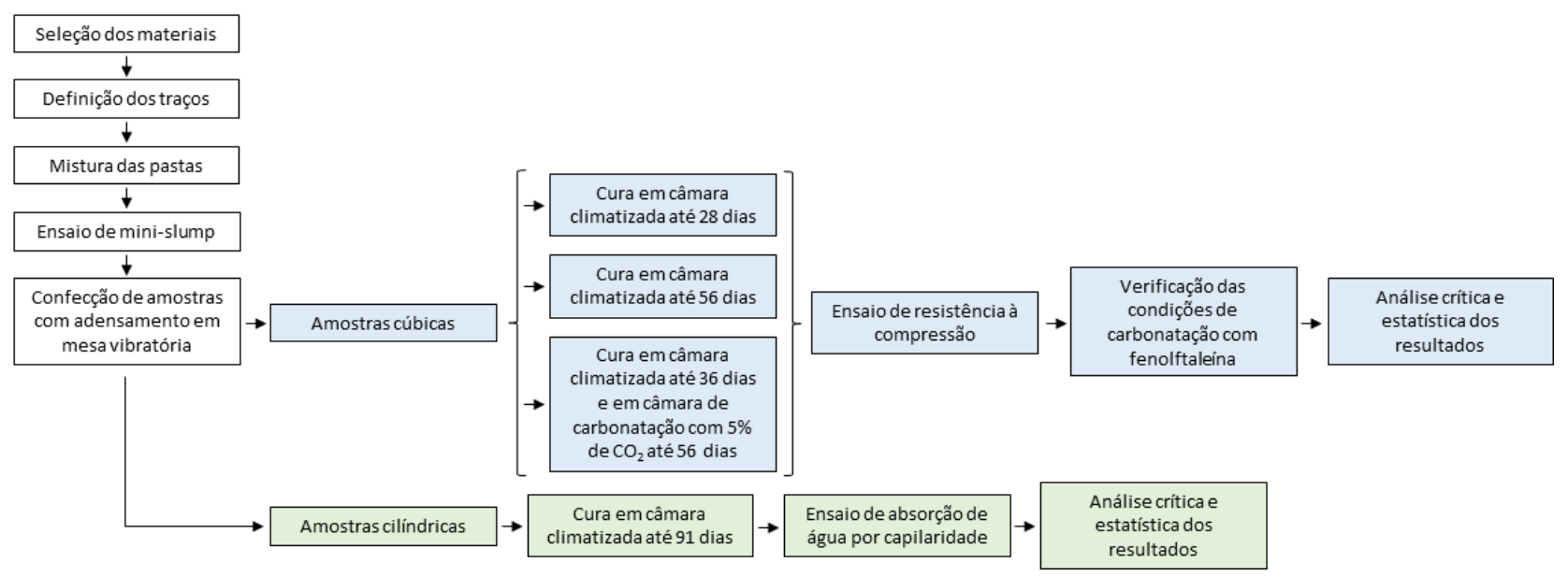

Figura 1 - Fluxograma das etapas de seleção de materiais, dosagem, moldagem, cura e realização de ensaios

\subsection{Materiais}

As pastas foram produzidas com cal hidráulica e cal hidratada $\mathrm{CH}-\mathrm{I}$ em diferentes proporções. A cal hidratada apresenta massa específica de $2.306 \mathrm{~g} / \mathrm{cm}^{3}$, determinada conforme a NM 23 (ABNT, 2000), e massa unitária de $0.522 \mathrm{~g} / \mathrm{cm}^{3}$, e a cal hidráulica apresenta massa específica de $2.565 \mathrm{~g} / \mathrm{cm}^{3}$ e massa unitária de $0.637 \mathrm{~g} / \mathrm{cm}^{3}$.

\subsection{Dosagem, moldagem e cura das pastas de cal}

As proporções de cal hidráulica e hidratada adotadas neste estudo foram, respectivamente: $100 \%$ e $0 \%$; $90 \%$ e $10 \% ; 70 \%$ e $30 \% ; 50 \%$ e $50 \%$. A definição dessas proporções levou em consideração resultados como o do trabalho de Garijo et al. (2020), que apresenta valores de propriedades mecânicas para argamassas com cal hidráulica natural superiores aos respectivos valores para argamassas de cal aérea contendo entre 90-95\% de portlandita $\left(\mathrm{Ca}(\mathrm{OH})_{2}\right)$, avaliando idades de até 448 dias. As argamassas de Garijo et al. (2020) foram todas confeccionadas com traço aglomerante/agregado 1:3 e relação água/aglomerante 0.9 , ambos em volume.

Com as proporções definidas, esperava-se, portanto, limitar a maior resistência mecânica e a menor absorção de água por capilaridade para a mistura com $100 \%$ do aglomerante hidráulico, e observar a influência da adição de cal hidratada nos resultados até uma proporção de 1:1. Essa foi a proporção utilizada para a mistura de cal aérea e cal hidráulica confeccionada por Magalhães e Veiga (2005).

No procedimento de moldagem, foram utilizados $600 \mathrm{~g}$ de materiais secos. Os materiais secos e a água foram adicionados à cuba de uma argamassadeira de bancada, sendo misturados durante 60 segundos em velocidade lenta (140 rpm, conforme a NBR 7215 (ABNT, 2019)), seguidos de 60 segundos na velocidade rápida (285 rpm em torno do eixo (ABNT, 2019)); após a raspagem da cuba visando desprender o material das paredes, a pasta foi misturada por mais 30 segundos em velocidade rápida. A quantidade de água

Contrib. à análise de pastas de cal hidráulica e hidrat. p/reparos em rev. de fachadas de edif. hist. 
adicionada permitiu obter uma média de $80 \pm 10 \mathrm{~mm}$ em três medidas do ensaio de mini-slump; dessa forma, as pastas apresentaram trabalhabilidade adequada à moldagem e semelhante entre si. O Quadro 1 apresenta a quantidade de materiais secos e água utilizada na confecção das pastas, a relação água/aglomerante e a média entre as medidas do ensaio de mini-slump, que consistiu na adição da pasta a um molde tronco-cônico em uma única camada sem compactação e posterior remoção deste molde verticalmente, com medição do diâmetro de abertura da pasta, de forma similar ao descrito por Kantro (1980).

Quadro 1 - Quantidade de materiais secos e água utilizados na confecção das pastas, relação água/aglomerante e valor médio de mini-slump

\begin{tabular}{|c|c|c|c|c|c|}
\hline Traço & $\begin{array}{c}\text { Cal } \\
\text { hidráulica } \\
\text { [g] }\end{array}$ & $\begin{array}{c}\text { Cal } \\
\text { hidratada } \\
\text { [g] }\end{array}$ & $\begin{array}{c}\text { Água } \\
\text { [g] }\end{array}$ & $\begin{array}{c}\text { Relação } \\
\text { água/ } \\
\text { aglomerante }\end{array}$ & $\begin{array}{c}\text { Mini- } \\
\text { slump } \\
\text { [mm] }\end{array}$ \\
\hline $100 \%$ cal hidráulica & 600 & - & 372 & 0.62 & 86.84 \\
\hline $90 \%$ cal hidráulica e 10\% cal hidratada & 540 & 60 & 370 & 0.62 & 80.72 \\
\hline $70 \%$ cal hidráulica e 30\% cal hidratada & 420 & 180 & 373 & 0.62 & 75.09 \\
\hline $50 \%$ cal hidráulica e 50\% cal hidratada & 300 & 300 & 381 & 0.64 & 73.38 \\
\hline
\end{tabular}

Após a mistura das pastas, foram confeccionadas para cada traço amostras cúbicas de lado $20 \mathrm{~mm}$ e amostras cilíndricas de diâmetro e altura de $20 \mathrm{~mm}$ e $40 \mathrm{~mm}$, respectivamente. O preenchimento das formas ocorreu em duas camadas e o adensamento foi realizado com auxílio de mesa vibratória. Na sequência, as amostras foram mantidas em câmara climatizada, com temperatura $\left(21.5^{\circ} \mathrm{C} \pm 1.5^{\circ} \mathrm{C}\right)$ e umidade $(80.5 \% \pm 0.5 \%)$ controladas, até a realização dos ensaios de resistência à compressão e absorção de água por capilaridade. Além das amostras curadas em ambiente climatizado, para o ensaio de resistência à compressão aos 56 dias, 5 amostras de cada traço foram expostas em uma câmara de carbonatação com $5 \%$ de $\mathrm{CO}_{2}$ durante os 20 dias finais do período, permancendo os primeiros 36 dias na câmara climatizada junto das demais amostras.

\subsection{Caracterização das pastas de cal no estado endurecido}

O ensaio de resistência à compressão foi realizado com as amostras cúbicas em uma máquina universal EMIC modelo DL2000, observando-se as recomendações da NBR 7215 (ABNT, 2019). Antes da ruptura, as faces dos cubos foram previamente preparadas com auxílio de lixas, buscando deixá-las planas e sem irregularidades. As rupturas foram realizadas aos 28 e aos 56 dias em 5 amostras de cada traço curadas apenas em câmara climatizada; além disso, aos 56 dias, também foram rompidas 5 amostras de cada traço mantidas inicialmente em câmara climatizada e nos últimos 20 dias em câmara de carbonatação. Após a ruptura das amostras, aspergiu-se fenolftaleína (1\% dissolvida em álcool etílico) para identificar as condições de carbonatação.

O ensaio de absorção de água por capilaridade foi realizado com as amostras cilíndricas, sendo 5 de cada proporção de cal hidráulica e hidratada. Este ensaio foi realizado aos 91 dias, período durante o qual as amostras foram mantidas em câmara climatizada. As diretrizes do ensaio basearam-se nas recomendações da NBR 9779 (ABNT, 2012), com adaptações: no caso das pastas, as amostras foram pesadas em balança analítica ao iniciar o ensaio e após 1 minuto, 2 minutos e 5 minutos de contato com a lâmina d'água.

\subsection{Método de análise}

Para embasar a análise crítica, foram realizadas análises estatísticas com auxílio do software Statistica 7 (STATSOFT, 2004). Análises de Variância (ANOVAs) com intervalo de confiança de $95 \%$ foram desenvolvidas para a variável de resposta resistência à compressão considerando como fatores controláveis, na primeira análise, a idade de ensaio e o traço, contemplando, portanto, as amostras ensaiadas aos 28 e 56 dias curadas em câmara climatizada, e, na segunda análise, o traço e o tipo de cura, considerando, assim, as amostras rompidas aos 56 dias expostas ou não em câmara de carbonatação. Uma terceira ANOVA avaliou a absorção de água por capilaridade. Para as comparações múltiplas de médias, efetuou-se o teste de Duncan, sendo a diferença entre médias significativa quando a hipótese nula é rejeitada, ou seja, o valor- $p$ é menor que 0.05 . 
Para as análises dos resultados de resistência à compressão, as amostras que conduziram a coeficientes de variação superiores a $30 \%$ foram desconsideradas. Ainda assim, a obtenção da resistência à compressão média foi calculada contemplando resultados de pelo menos 3 amostras. Para a absorção de água por capilaridade, os coeficientes de variação foram todos inferiores a 7\% e nenhuma amostra foi desconsiderada.

\section{Resultados e discussão}

A Figura 2 ilustra o teste de Duncan realizado no software Statistica 7 (STATSOFT, 2004) para os resultados de resistência à compressão das amostras aos 28 dias e aos 56 dias, curadas somente em câmara climatizada. O teste foi efetuado para a combinação entre idade de ensaio e traço, já que os dois fatores controláveis individuais e a interação entre eles foram significativos, conforme a ANOVA, a um intervalo de confiança de $95 \%$. Considerou-se que há diferença estatisticamente significativa entre as médias se $p$ é menor do que 0.05 .

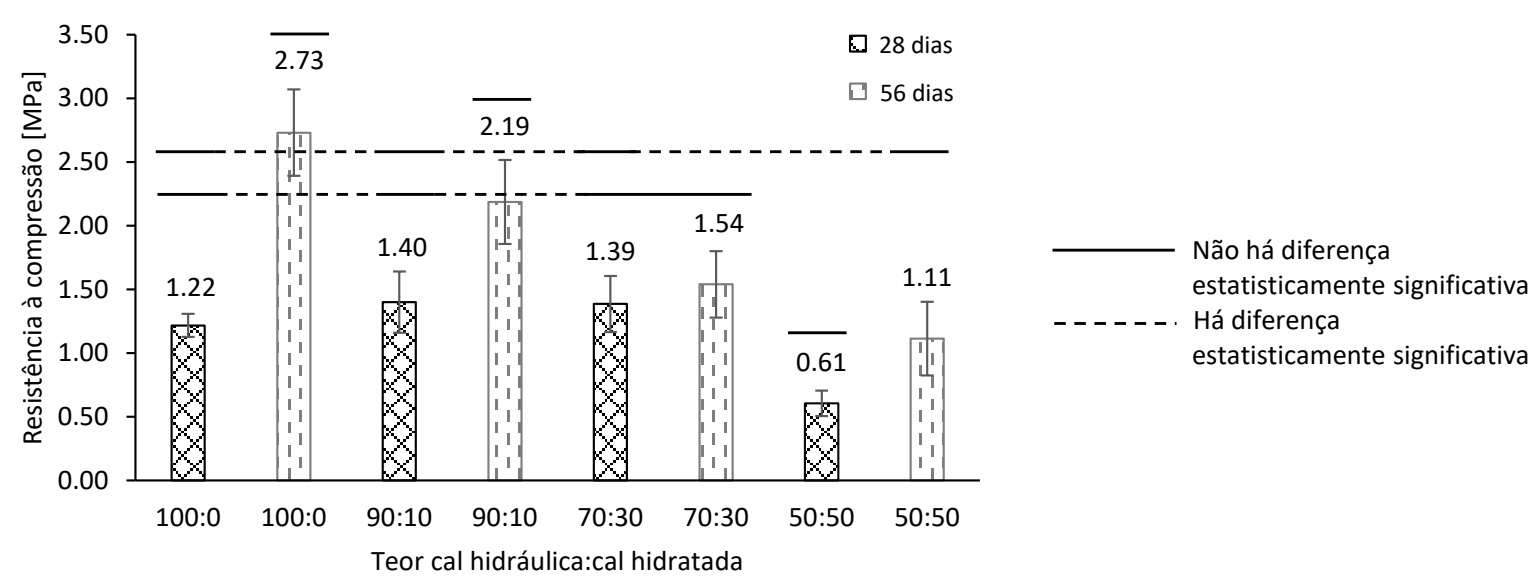

Figura 2 - Resultados do teste de Duncan para comparação múltipla de médias entre a resistência à compressão das amostras aos 28 dias e 56 dias, com cura somente em câmara climatizada

Aos 28 dias, somente o traço com $50 \%$ de cada tipo de cal apresentou diferença estatisticamente significativa em relação aos demais na mesma idade, que foram superiores, conforme a Figura 2. O maior teor de cal hidratada pode ter contribuído para essa menor resistência, já que a cal hidráulica apresenta, além do hidróxido de cálcio, silicatos e aluminatos que reagem de forma análoga à do cimento (CINCOTTO et al., 2007). As reações apresentadas pelo cimento conduzem a maiores resistências nos estágios iniciais de cura das misturas, já as reações exclusivas da cal são mais lentas, contribuindo especialmente para a resistência a longo prazo (NAGARAJ et al., 2014). Segundo Lanas et al. (2004), além disso, a carbonatação das argamassas de cal contribui menos para a resistência à compressão do que os componentes hidráulicos.

Aos 56 dias, na análise da Figura 2, todos os traços apresentaram resistências com diferença estatisticamente significativa entre si e com valores crescentes conforme o aumento no teor de cal hidráulica. Com exceção das pastas com $70 \%$ do aglomerante hidráulico, todas as demais apresentaram aumento na resistência em relação aos 28 dias. Esse aumento pode ter contribuição das reações de carbonatação, conforme sugerido pela Figura 3: o teste com aspersão de fenolftaleína no interior das amostras após a sua ruptura aos 56 dias permitiu identificar maior profundidade de carbonatação em comparação às amostras com 28 dias.
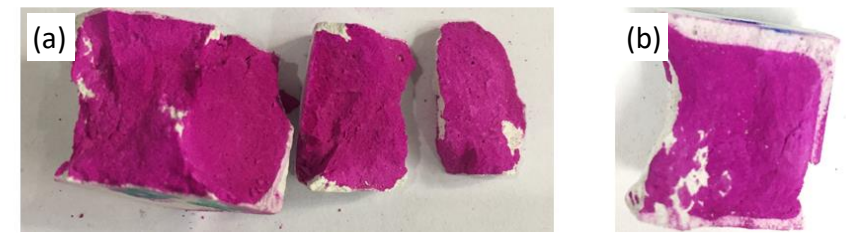

Figura 3 - Aspersão de fenolftaleína em amostras com 90\% de cal hidráulica e 10\% hidratada aos (a) 28 e (b) 56 dias 
A Figura 4 apresenta o teste de Duncan efetuado no software Statistica 7 (STATSOFT, 2004) para a resistência à compressão aos 56 dias, contemplando as amostras curadas apenas em câmara climatizada e as mantidas nos 20 dias finais de cura em câmara de carbonatação. Na ANOVA, traço, tipo de cura e a sua interação foram significativos, por isso, o teste de Duncan refere-se aos tratamentos (combinação dos fatores controláveis); a diferença entre médias é significativa caso a hipótese nula seja rejeitada com $p$ menor que 0.05 .

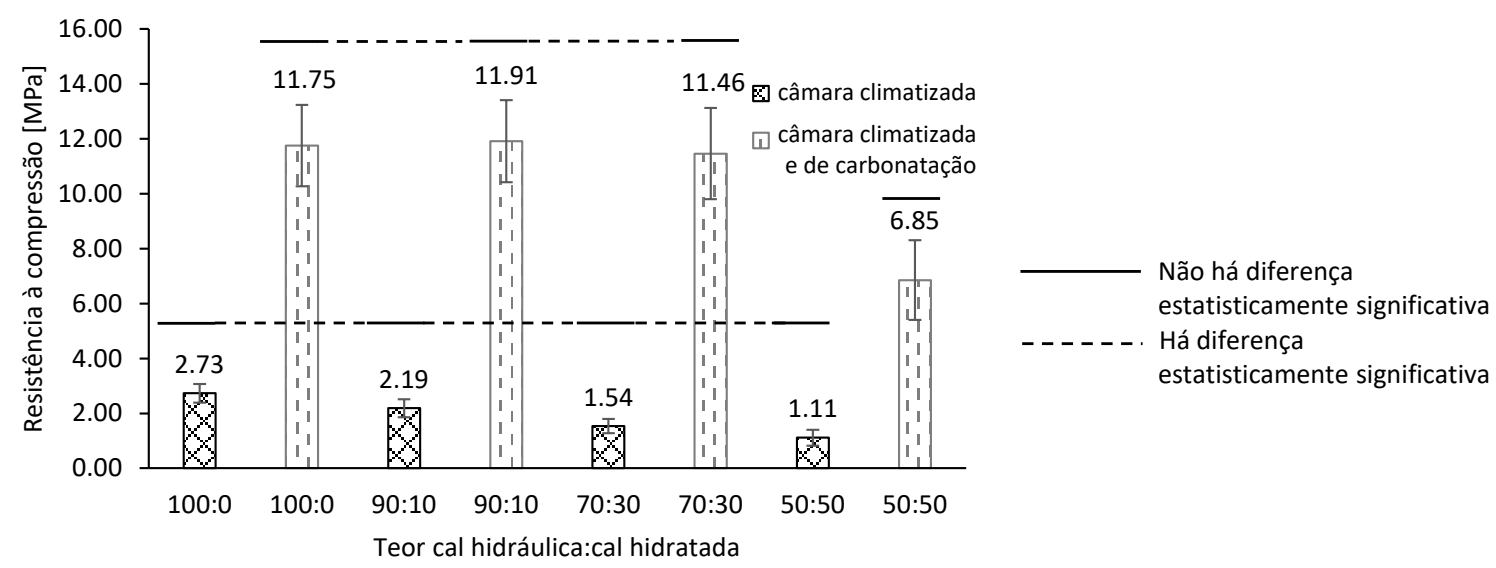

Figura 4 - Resultados do teste de Duncan para a resistência à compressão das amostras aos 56 dias, considerando cura somente em câmara climatizada ou contemplando também câmara de carbonatação nos 20 dias finais

Na análise da Figura 4, aos 56 dias, as resistências das amostras curadas apenas em câmara climatizada não apresentaram diferença estatisticamente significativa entre as quatro proporções ensaiadas. É expressiva a contribuição da exposição das amostras em câmara de carbonatação nos 20 dias finais de cura; essas amostras não apresentaram área na cor rosa ao serem aspergidas com fenolftaleína, indicando que houve carbonatação de toda sua superfície, o que ajuda a explicar as resistências pelo menos 4 vezes superiores às dos traços correspondentes curados apenas em câmara climatizada. A carbonatação de argamassas de cal é um processo muito lento, podendo levar anos até a carbonatação total (VÁZQUEZ, 2002). A cura das amostras em câmara com $\mathrm{CO}_{2}$ neste trabalho acelerou, portanto, a taxa natural de ocorrência dessa reação.

Os resultados das amostras expostas em câmara de carbonatação (Figura 4) sugerem que, a longo prazo, amostras com $70 \%$ ou mais de cal hidráulica poderiam apresentar um comportamento similar em termos de resistência à compressão, enquanto amostras com $50 \%$ de cada cal apresentam resistências inferiores, mas, ainda assim, maiores que aquelas das amostras curadas em câmara climatizada, sem carbonatação total. Ressalta-se, contudo, que os maiores valores de resistência das amostras com pelo menos $70 \%$ de cal hidráulica não são necessariamente melhores, pois as propriedades dos materiais utilizados como reparo em edificações históricas devem ser compatíveis às dos materiais pré-existentes. Além da compatibilidade química, é fundamental que se verifique a compatibilidade quanto à resistência das argamassas, propondose, no restauro, argamassas com menor resistência que a original, para evitar o surgimento de tensões.

A Figura 5 apresenta o teste de Duncan para a absorção de água por capilaridade, realizado no software Statistica 7 (STATSOFT, 2004); a diferença entre médias é significativa se $p$ é menor que 0.05 . 0 teste aborda a combinação de fatores controláveis, pois, traço, tempo de ensaio e a interação são significativos na ANOVA. Conforme a Figura 5, a maioria dos traços apresentou diferença estatisticamente significativa entre sua absorção de água por capilaridade, especialmente aos 2 e 5 minutos de ensaio. Em 1 minuto, entre as amostras com $90 \%$ e $70 \%$ de cal hidráulica e entre as amostras com $70 \%$ e $50 \%$ desse aglomerante não houve diferença estatisticamente significativa, o que sugere que a absorção inicial é semelhante entre esses traços. Observa-se, porém, que, em geral, quanto menor o teor de cal hidráulica (e maior o teor de cal hidratada), maior é a absorção por capilaridade, independentemente do momento avaliado; ainda, quanto mais longo o período de ensaio, maior a quantidade de água absorvida, conforme esperado. Há uma tendência de maior absorção pelas amostras com menor resistência à compressão. Essa tendência também era esperada: argamassas antigas com maiores resistências usualmente apresentam os menores valores de absorção por capilaridade nos primeiros minutos, em relação a argamassas com menores resistências (VEIGA et al., 2004b). 


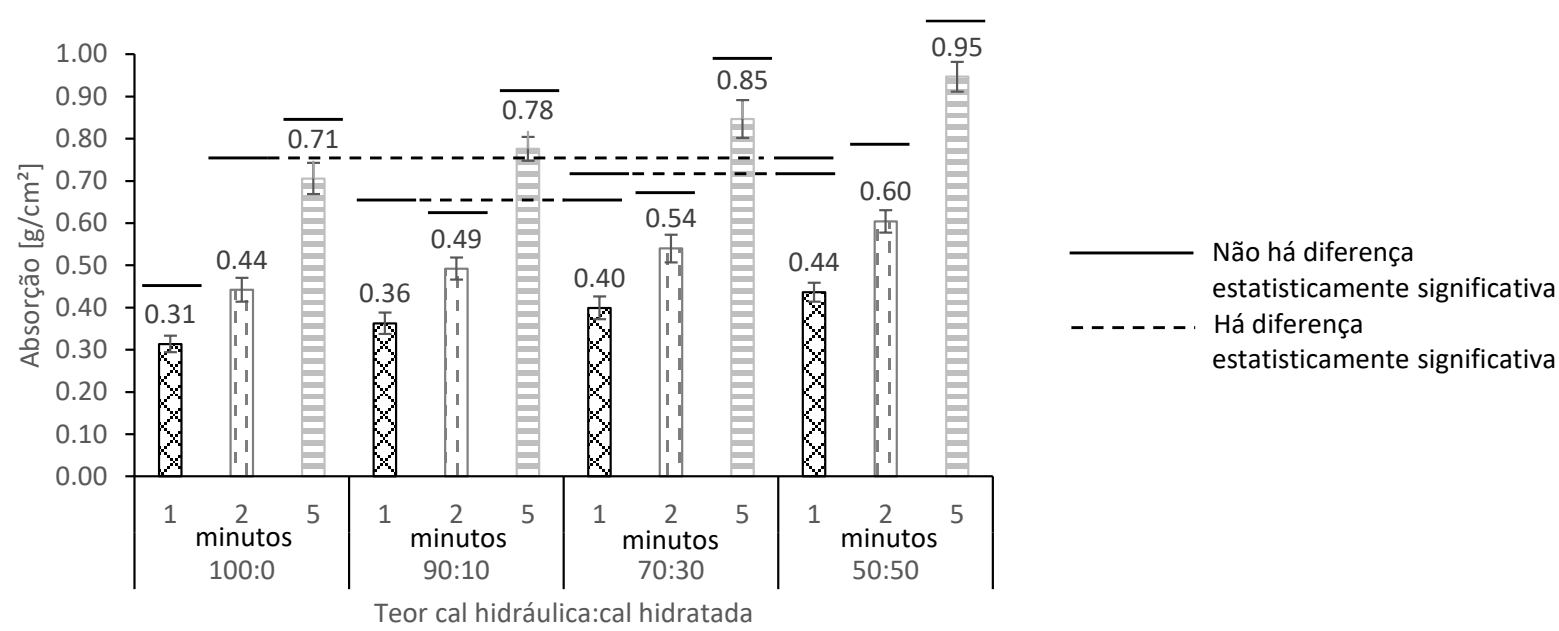

Figura 5 - Resultados do teste de Duncan para comparação múltipla de médias da absorção de água por capilaridade das amostras aos 91 dias, considerando 1, 2 e 5 minutos após contato com a lâmina d'água

\section{Conclusões}

Neste trabalho, foram analisadas pastas com diferentes proporções de cal hidráulica e cal hidratada, usuais em revestimentos de fachadas históricas. Objetivou-se contribuir na escolha de argamassas para reparos.

Após 28 dias de cura em câmara climatizada, as pastas com $50 \%$ de cada tipo de cal apresentaram os menores valores de resistência à compressão, provavelmente devido ao teor mais baixo de cal hidráulica, não havendo diferença estatisticamente significativa entre as amostras com 70\%, 90\% e 100\% desse aglomerante. Aos 56 dias, as resistências, em geral, foram maiores que aos 28 dias, podendo ter havido contribuição da carbonatação. Nessa análise, aos 56 dias, os valores foram crescentes conforme o incremento no teor de cal hidráulica. A exposição em câmara de carbonatação nos 20 dias finais para amostras rompidas aos 56 dias gerou aumentos de pelo menos 4 vezes nas resistências à compressão; as amostras com $50 \%$ de cal hidráulica apresentaram os menores valores e entre as demais não houve diferença estatisticamente significativa.

Os valores de absorção de água por capilaridade foram crescentes ao longo do período de ensaio. Em geral, também aumentaram para maiores teores de cal hidratada, de forma coerente à resistência à compressão.

A caracterização física, química e mecânica dos materiais originais de cada edificação histórica a ser reparada é fundamental para sua preservação. $O$ entendimento da influência da adição de diferentes teores de cal hidratada e cal hidráulica em pastas pode facilitar a dosagem de argamassas de reparo, sugerindo alternativas para se atingir a compatibilidade dos novos materiais com os pré-existentes na edificação.

\section{Agradecimentos}

Os autores agradecem ao suporte financeiro do CNPq (Conselho Nacional de Desenvolvimento Científico e Tecnológico) e da CAPES (Coordenação de Aperfeiçoamento de Pessoal de Nível Superior), ao LAMTAC (Laboratório de Materiais e Tecnologia do Ambiente Construído), ao PPGCI (Programa de Pós-Graduação em Engenharia Civil: Construção e Infraestrutura) e à UFRGS (Universidade Federal do Rio Grande do Sul).

\section{Referências Bibliográficas}

ABNT - Associação Brasileira de Normas Técnicas. (2000). NM 23: Cimento Portland e outros materiais em pó - Determinação da massa específica. Rio de Janeiro.

ABNT - Associação Brasileira de Normas Técnicas. (2019). NBR 7215: Cimento Portland - Determinação da resistência à compressão de corpos de prova cilíndricos. Rio de Janeiro.

ABNT - Associação Brasileira de Normas Técnicas. (2012). NBR 9779: Argamassa e concreto endurecidos Determinação da absorção de água por capilaridade. Rio de Janeiro. 
Alvarez, J., Sequeira, C., Costa, M. (2005). Ensinamentos a retirar do Passado Histórico das Argamassas. 1을 Congresso Nacional de Argamassas de Construção - APFAC, Lisboa, Portugal; novembro 2005.

Arandigoyen, M., Bernal, J.L.P., López, M.A.B., Alvarez, J.I. (2005). Lime-pastes with different kneading water: Pore structure and cappilary porosity. Appl. Surf. Sci., 252 (5), 1449-1459.

Araújo, E., Souza, I., Paz, R., Costa, C.H., Mesquita, E. (2020). Physical and mechanical characterization of traditional Brazilian clay bricks from different centuries. J. Build. Rehabil., 5 (22).

Barbero-Barrera, M. Del M., Maldonado-Ramos, L., Van Balen, K., García-Santos, A., Neila-González, F.J. (2014). Lime render layers: An overview of their properties. J. Cult. Herit., 15 (3), 326-330.

Bauer, E., Piazzarollo, C.B., De Souza, J.S., Dos Santos, D.G. (2020). Relative importance of pathologies in the severity of facade degradation. J. Build. Rehabil., 5 (7).

Bersch, J.D., Verdum, G., Guerra, F.L., Socoloski, R.F., Giordani, C., Zucchetti, L., Masuero, A.B. (2020). Diagnosis of Pathological Manifestations and Characterization of the Mortar Coating from the Facades of Historical Buildings in Porto Alegre - Brazil: A Case Study of Château and Observatório Astronômico. Int. J. Archit. Heritage.

Cincotto, M.A., Quarcioni, V.A., John, V.M. (2007). Cal na construção civil. In: Geraldo C Isaia. (Org.). Materiais de Construção Civil e Principios de Ciência e Engenharia de Materiais. São Paulo: IBRACON, v.1, 695-726.

Flores-Colen, I., De Brito, J., De Freitas, V.P. (2009). Métodos de Verificação do Desempenho em Serviço de Fachadas Rebocadas. 3 Encontro Nacional sobre Patologia e Reabilitação de Edifícios - Patorreb 2009, Porto, Portugal; fevereiro 2009.

Garijo, L., Zhang, X., Ruiz, G., Ortega, J.J. (2020). Age effect on the mechanical properties of natural hydraulic and aerial lime mortars. Constr. Build. Mater., 236, 117573.

Guerra, F.L., Giordani, C., Volpatto, L., Gonçalves, J.P., De Oliveira, M.M., Masuero, A.B., Dal Molin, D.C.C. (2020). Physicochemical Characterization of Historical Coating Mortars - Case Studies in South Brazil. Int. J. Archit. Heritage.

Kantro, D.L. (1980). Influence of Water-Reducing Admixtures on Properties of Cement Paste - A Miniature Slump Test. Cem. Concr. Aggreg., 2 (2), 95-102.

Lanas, J., Bernal, J.L.P., Bello, M.A., Galindo, J.I.A. (2004). Mechanical properties of natural hydraulic limebased mortars. Cem. Concr. Res., 34 (12), 2191-2201.

Magalhães, A.C., Veiga, M. do R. (2005). Estudo comparativo de possíveis soluções de argamassas para revestimentos de paredes de edifícios antigos. 1ㅇ Congresso Nacional de Argamassas de Construção APFAC, Lisboa, Portugal; novembro 2005.

Nagaraj, H.B., Sravan, M.V., Arun, T.G., Jagadish, K.S. (2014). Role of lime with cement in long-term strength of Compressed Stabilized Earth Blocks. Int. J. Sustain. Built Environ., 3 (1), 54-61.

Rani, S.D., Rahul, A. V., Santhanam, M. (2021). A multi-analytical approach for pore structure assessment in historic lime mortars. Constr. Build. Mater., 272, 121905.

StatSoft, Inc. (2004). STATISTICA (sistema de software de análise de dados), versão 7. www.statsoft.com.

Vázquez, O.C. (2002). Morteros de cal. Aplicación en el patrimonio histórico. Tese de doutoramento. Departamento de Mineralogía y Petrología. Universidad de Granada, Espanha.

Veiga, M. Do R., Aguiar, J., Silva, A.S., Carvalho, F. (2004a). Conservação e renovação de revestimentos de paredes de edifícios antigos. Lisboa: Laboratório Nacional de Engenharia Civil. 126 p.

Veiga, M.R., Magalhães, A.C., Bokan-Bosilikov, V. (2004b). Capillarity tests on historic mortar samples extracted from site. Methodology and compared results. $13^{\text {th }}$ International Brick and Block Masonry Conference, Amsterdã, Holanda; julho 2004.

Zhang, D., Zhao, J., Wang, D., Xu, C., Zhai, M., Ma, X. (2018). Comparative study on the properties of three hydraulic lime mortar systems: Natural hydraulic lime mortar, cement-aerial lime-based mortar and slagaerial lime-based mortar. Constr. Build. Mater., 186, 42-52. 